Pure Appl. Chem., Vol. 73, No. 3, pp. 567-571, 2001.

(C) 2001 IUPAC

\title{
Natural products from around the world*
}

\author{
J. D. Connolly \\ Chemistry Department, University of Glasgow, Glasgow G12 8QQ, Scotland
}

Abstract: The structures of a range of natural products from Africa, Nepal, and Chile will be discussed.

In principle, computer-assisted structure elucidation should facilitate the task of natural product chemists and speed up the process of resolving the structures of the many, often known, compounds that they isolate from natural sources. We have used the Logic for Structure Determination (LSD) program, developed by Dr. Jean-Marc Nuzillard of the University of Reims, France, to solve the structures of some diterpenoids from Salvia henkei [1]. These compounds presented no particular difficulties and could have been readily resolved without recourse to the computer by normal spectral analysis. Recently, we were challenged by the structures of three alkaloids, from the seeds of Acosmium panamense (Fabaceae), which defied all our efforts to find solutions without using the LSD program [2]. Column chromatography of the crude alkaloid mixture obtained from the seed extract afforded six compounds, four of them new. The two known alkaloids were readily identified as lupanine and multiflorine while one of the new compounds was assigned the structure $4 \alpha$-angeloyloxy- $3 \beta$-hydroxy-13 $\beta$ methoxylupanine $\mathbf{1}$. The remaining three new compounds are acosmine $\mathbf{2}$, acosmine acetate $\mathbf{3}$, and panacosmine 4.

Acosmine 2 has the molecular formula $\mathrm{C}_{21} \mathrm{H}_{33} \mathrm{~N}_{3} \mathrm{O}_{2}(\mathrm{~m} / \mathrm{z}$ 359). It contains an unusual $N$-acetyl enamine in addition to a vinyl group, a primary hydroxyl group, and two tertiary amines. The large coupling between the $\mathrm{NH}$ and the vinyl proton of the trisubstituted double bond $(\mathrm{J}=11 \mathrm{~Hz})$ confirms the presence of the enamine moiety. From COSY, HSQC and HMBC spectra several part structures could be deduced but a definitive structure proved elusive. The remaining bonds were deduced using HSQC and HMBC correlations as input to the LSD program. A single solution 2 was found in $0.1 \mathrm{~s}$. Structure 2 is closely related to the lupanine/angustifoline skeleton. C-20 bridges the two nitrogens of a diazabicyclo[3.3.1]nonane system to form a diaza-adamantane skeleton, novel in natural product chemistry. The relative configurations of 2 follow from the constraints of the skeleton (C-7 and C-9 drawn to agree with those of lupanine) and from correlations in the ROESY spectrum. Disconnection of C-20 from $\mathrm{N}-1$ and N-12 affords a molecule whose absolute configurations are the same as those of the corresponding centers in lupanine and angustifoline. Further support for the structure of acosmine was obtained from correlations in the ${ }^{1} \mathrm{H}-{ }^{15} \mathrm{~N}$ HMBC spectrum of the second new alkaloid, the corresponding primary acetate, acosmine acetate 3. Inter alia, correlations were observed from $\mathrm{H}-20$ to both $\mathrm{N}-1$ and $\mathrm{N}-12$ and from $\mathrm{H}-21$ to $\mathrm{N}-22$.

The final compound, panacosmine 4 , has the molecular formula $\mathrm{C}_{21} \mathrm{H}_{31} \mathrm{~N}_{3} \mathrm{O}\left[\mathrm{m} / \mathrm{z} 342\right.$, $\left.(\mathrm{M}+1)^{+}\right]$. It exists as a mixture of amide rotamers (4:1) and this complicates spectral analysis because of superposition of signals. The resonances of the major component were used for the analysis with the LSD program. This provided 32 solution structures. In order to reduce this number a requirement that the solutions should contain the $\mathrm{B}, \mathrm{C}$ ring system of angustifoline was introduced. Only two structures remained, of which $\mathbf{4}$ was preferred since it has the A,B,C ring system of angustifoline. Structure $\mathbf{4}$ also represents

*Lecture presented at the $22^{\text {nd }}$ IUPAC International Symposium on the Chemistry of Natural Products, São Carlos, Brazil, 3-8 September 2000. Other presentations are published in this issue, pp. 549-626. 
the major amide rotamer since the vinyl proton of the minor rotamer is deshielded $(\Delta \delta=0.6 \mathrm{ppm})$ by the carbonyl group.

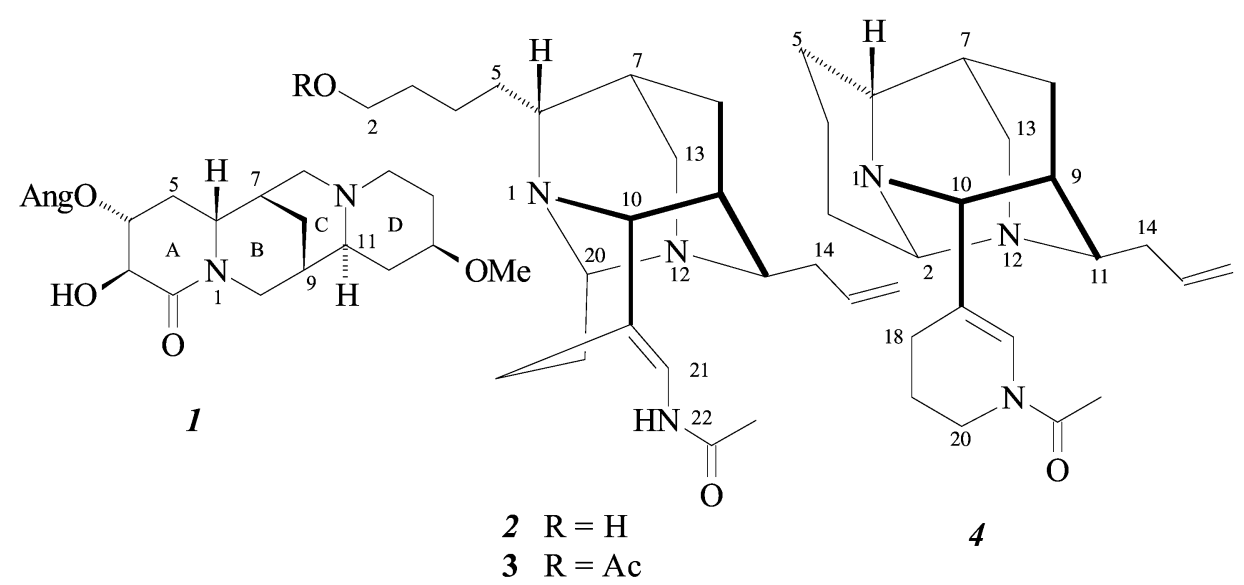

Chromatography of the methanol extract of the thalloid liverwort Marchantia paleacea Betrol subsp. paleacea, collected in Nepal, afforded the bisbibenzyl derivatives marchantins A, C, and D, 2hydroxy-3,7-dimethoxyphenanthrene and the interesting new compound, 3,4-dihydro-8-hydroxy-4-(4'hydroxyphenyl)-isocoumarin 5 [3]. Compound 5 was obtained as a gum. Its ${ }^{1} \mathrm{H}$ NMR spectrum revealed two aromatic rings, one para-disubstituted $\left[\delta_{\mathrm{H}} 6.99\right.$ and 6.76 (AA'BB', $J=8.6 \mathrm{~Hz}, \mathrm{H}-2^{\prime}, 6^{\prime}$ and $\left.\mathrm{H}-3^{\prime}, 5^{\prime}\right)$ ] and the other with three contiguous protons $\left[\delta_{\mathrm{H}} 7.33(\mathrm{t}, J=7.9 \mathrm{~Hz}, \mathrm{H}-6), 6.86(\mathrm{~d}, J=8.4 \mathrm{~Hz}, \mathrm{H}-5)\right.$ and $6.41(\mathrm{~d}, J=7.5 \mathrm{~Hz}, \mathrm{H}-7)]$, a bonded hydroxyl proton $\left[\delta_{\mathrm{H}} 11.04(\mathrm{~s}, 8-\mathrm{OH})\right]$, and a three spin system $\mathrm{CH}-\mathrm{CH}_{2}[\mathrm{ABX}]$ with the methylene group attached to oxygen $\left[\delta_{\mathrm{H}} 4.57(\mathrm{dd}, J=11.0,5.0 \mathrm{~Hz}, \mathrm{H}-3), 4.50\right.$ (dd, $J=11.0,8.6 \mathrm{~Hz}, \mathrm{H}-3), 4.21$ (dd, $J=5.0,8.6 \mathrm{~Hz}, \mathrm{H}-4)]$. The carbon spectrum confirmed the presence of the two aromatic rings and the $\mathrm{CH}-\mathrm{CH}_{2}-\mathrm{OR}$ system and additionally revealed the presence of an ester/lactone carbonyl group at $\delta_{\mathrm{C}} 170.0$.

The spin systems were readily observed in the COSY spectrum and the assignment of the protonated carbons followed from the HMQC spectrum. The above data can be assembled to give the 3,4dihydroisocoumarin structure 5. Confirmation of the structure of $\mathbf{5}$ was obtained from correlations in the HMBC spectrum which also permitted the assignment of the non-protonated carbons. Despite its simple structure the 3,4-dihydroisocoumarin $\mathbf{5}$ is a new natural product and has not been reported previously. Isocoumarins are usually polyketide in origin and are normally substituted on position 3 . The isocoumarin hydrangenol $\mathbf{6}$, clearly a derivative of lunularic acid, has been reported in a liverwort by Becker and his colleagues [4].<smiles>O=C1OCC(c2ccc(O)cc2)c2cccc(O)c21</smiles>

5<smiles>O=C1OC(c2ccc(O)cc2)Cc2cccc(O)c21</smiles>

6 
The formation of bifarnesol 7 seems the obvious first step in the conversion of farnesol into presqualene alcohol. Over a decade ago we isolated an anhydro-derivative of bifarnesol from the latex of Euphorbia lateriflora [5]. The structure 8, proposed for this compound on the basis of its spectroscopic properties, has now been confirmed by synthesis [6]. The synthetic route is based on work on the photoisomerization of $\alpha, \beta$-unsaturated esters into their $\beta, \gamma$-unsaturated isomers carried out previously by Prof. Piva and his colleagues. Methyl acetoacetate was conveniently $\gamma$-alkylated (NaH, LDA) with geranyl bromide and then $\alpha$-alkylated (DBU) with farnesyl bromide. The resulting keto-ester 9 was converted to the corresponding enol phosphate which was smoothly transformed into the unsaturated ester $\mathbf{1 0}$ on treatment with dimethylcuprate in ether. Deconjugation of $\mathbf{1 0}$ by irradiation in dichloromethane in the presence of $N, N$-dimethylaminoethanol afforded the desired $\beta, \gamma$-unsaturated isomer which was reduced by $\mathrm{LiAlH}_{4}$ to give 8, identical with the natural compound. Recently, another isolation of $\mathbf{8}$ (peplusol) has been reported [7] from Euphorbia peplus and the absolute configuration established as in $\mathbf{8}$.<smiles>[R]C(=CCC=C(C)CCC=C(C)C)C(CO)CC=C(C)CCC=C(C)CCC=C(C)C</smiles><smiles>[R]C(C)=CCCC(=O)C(CC=C([R])C)C(=O)OC</smiles>

9

$7 \mathrm{R}=\mathrm{CH}_{3}, \mathrm{OH}$

$8 \quad \mathrm{R}=\mathrm{CH}_{2}$<smiles>[R]C(C)=CCCC(C)=C(CC=C([R])C)C(C)=O</smiles>

10

As part of an investigation of Chilean Baccharis species by Prof. Labbé and her colleagues $B$. racemosa was extracted and yielded a chlorine-containing cyclic peptide whose molecular formula, $\mathrm{C}_{27} \mathrm{H}_{37} \mathrm{~N}_{5} \mathrm{O}_{7} \mathrm{Cl}_{2}$ was established by FABMS $\left(614 / 616[\mathrm{M}+\mathrm{H}]^{+} ; 636 / 638[\mathrm{M}+\mathrm{Na}]^{+}\right)$. Analysis of the ${ }^{1} \mathrm{H}$ NMR spectrum in conjunction with the COSY, HSQC, and HOHAHA spectra enabled us to identify the constituent amino acids as $\beta$-phenylalanine, serine, $\alpha$-aminobutanoic acid (homoalanine), bishomothreonine, and dichloroproline. The correlations of the NH and other protons to the amide carbonyl carbons enabled the structure of the peptide to be deduced in a systematic manner leading to $\mathbf{1 1}$. While $\mathbf{1 1}$ is a new compound, it is closely related to astin A $\mathbf{1 2}$ from Aster tataricus [8], differing only in the presence of a bishomothreonine instead of a threonine residue. The stereochemistry is assigned by analogy with astin A.

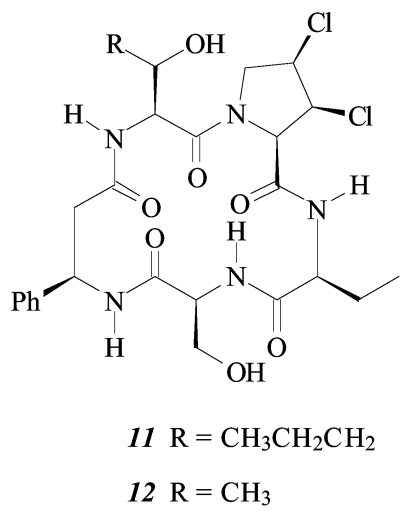


Luma chequen (Myrtaceae) is an aromatic, evergreen shrub native to Chile. Since this plant appears to be immune to insect attack the methanol extract of the leaves was investigated for the presence of antifeedant constituents. Initially, two crystalline compounds were isolated but one of these turned out to be a mixture of two closely related compounds which could be separated only by multiple preparative TLC. Both compounds had very simple ${ }^{1} \mathrm{H}$ NMR spectra—an isopropyl substituent coupled to a lowfield doublet, four tertiary methyls groups, an aromatic methyl group, a phenyl residue, an ABX system, and a strongly bonded hydroxyl group. These data suggested a methylflavanone structure with a fully substituted ring A. The similarity of the two compounds suggested they were stereoisomers. The ${ }^{13} \mathrm{C}$ NMR spectra revealed signals for three ketones, two of which are unsaturated, a phenyl ring, a fully substituted benzene ring, a fully substituted enolic double bond, and two quaternary aliphatic carbons. The structural units deduced from HMBC correlations could be assembled to give the gross structure 13. It was not possible to determine the relative stereochemistry by spectroscopic means, and so an X-ray crystal structure analysis (Dr. Farrugia, Glasgow) was undertaken. This revealed the stereochemistry as in $\mathbf{1 3}$ and also showed that the compound is racemic, suggesting that the original natural product is the corresponding chalcone which has undergone nonenzymatic cyclization to the flavanone. The other compound is presumably the cis-isomer. A third compound obtained from the extract is the corresponding hydrate in view of the hemiacetal carbon at $99.0 \mathrm{ppm}$ in the ${ }^{13} \mathrm{C}$ NMR spectrum.

Recently, a series of similar compounds, e.g., leucadenone A $\mathbf{1 4}$ has been reported from Melaleuca leucadendron [9]. These compounds are not racemates. There are many examples of modified phloroglucinol derivatives in the Myrtaceae family.

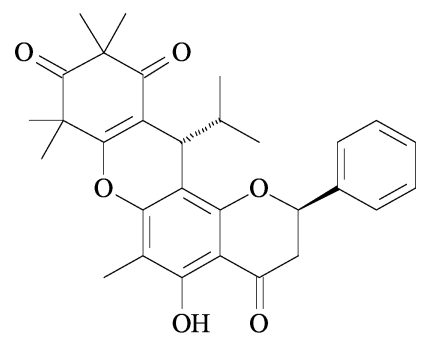

13

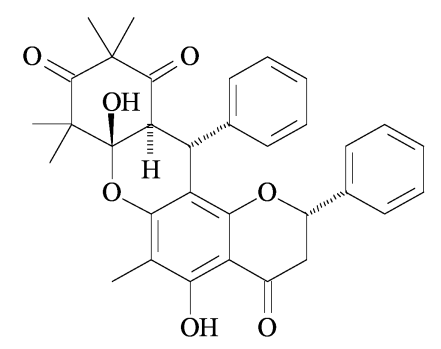

14

\section{ACKNOWLEDGMENTS}

I am grateful to Dr. J.-M. Nuzillard, Prof. C. Lavaud, and Ms S. Faure (University of Reims), Prof. O. Piva (University of Lyon), Prof. C. O. Fakunle (Obafeme Awolowo University, Nigeria), Mrs. R. Pandey (Kathmandu, Nepal), Prof. C. Labbé and her colleagues (University of Chile), Prof. J. A. Ayafor and his colleagues (University of Dschang, Cameroon), and Dr. D. S. Rycroft and Dr. L. Farrugia (University of Glasgow) for their collaboration.

\section{REFERENCES}

1. G. Almanza, L. Balderrama, C. Labbé, C. Lavaud, G. Massiot, J.-M. Nuzillard, J. D. Connolly, L. J. Farrugia, D. J. Rycroft. Tetrahedron 53, 14719 (1997).

2. J.-M. Nuzillard, J. D. Connolly, C. Delaude, B. Richard, M. Zèches-Hanrot, L. Le Men-Olivier. Tetrahedron 55, 11511 (1999).

3. R. Pandey, M.Sc. Thesis, University of Glasgow, 2000.

4. S. Valcic, J. Zapp, H. Becker. Phytochemistry 44, 89 (1997).

5. J. D. Connolly. Rev. Latinoam. Quim. 25, 77 (1997). 
6. S. Faure, J. D. Connolly, C. O. Fakunle, O. Piva. Tetrahedron 56, 9647 (2000).

7. J.-L. Giner, J. D. Berkowitz, T. Andersson. J. Nat. Prod. 63, 267 (2000).

8. H. Morita, S. Nagashima, K. Takeya, H. Itokawa, Y. Iitaka. Tetrahedron 51, 1121 (1995).

9. C.-K. Lee. Tetrahedron Lett. 40, 7255 (1999). 